\section{Discussion}

Although some workers (Macintosh and Davey, 1970, 1972) have reported chromosome damage after in-vitro exposure of cells to diagnostic levels of ultrasound, their findings have not been reproduced by others (Bobrow et al., 1971; Boyd et al., 1971 ; Buckton and Baker 1972; Watts et al., 1972). In the present study chromosome damage could not be detected after eight hours' exposure to ultrasound at $3.5 \mathrm{~W} / \mathrm{cm}^{2}$, which is similar to intensities produced by some therapeutic equipment. Others (Coakley et al., 1971, 1972) have used very high pulsed power levels for shorter periods without observing significant chromosomal aberrations.

It seems probable from our in-vitro experiments and other in-vivo studies (Abdulla et al., 1971; Lucas et al., 1972) that chromosome damage is not caused by ultrasound when used as a diagnostic tool.

There is, however, evidence of another factor that might cause damage in other ways. Clumping of red cells was seen in this study, and aggregation of red cells with stasis of blood flow has been shown to occur in blood vessels of chick embryos (Dyson et al., 1971). If stasis occurs in a fetal blood vessel the interruption to blood flow could damage the rapidly developing tissues.

We therefore conclude that other factors may well set a safety limit to ultrasonic power level below that at which chromosomal damage occurs and that absence of such damage should not be relied on too heavily as a measure of safety. (Taylor and Pond, 1972).

We wish to thank Professor C. J. Dewhurst for his interest and encouragement. Also we are grateful for the help of Sonicaid Limited and the Department of Health and Social Security, who made this study possible.

Requests for reprints should be addressed to Dr. U. Abdulla, Nuffield Department of Obstetrics and Gynaecology, John Radcliffe Hospital, Oxford OX3 9DU.

\section{References}

Abdulla, U., et al. (1971). Lancet, 2, 829.

Bleaney, B. I., Blackbourn, P., and Kirkley, J. (1972). British fournal of

Radiology, 45, 354.
Bobrow, M., Blackwell, N., Unrau, A. E., and Bleaney, B. (1971). Fournal of Obstetrics and Gynaecology of the British Commonwealth, 78, 730.

Boyd, E., et al. (1971). British Medical fournal, 2, 501.

Buckton, K. E., and Baker, N. V. (1972). British fournal of Radiology, 45,

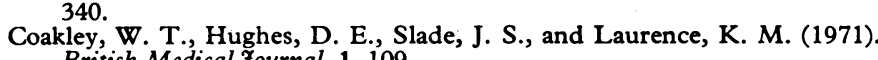
British Medical fournal, 1, 109.

Coakley, W. T., Slade, J. S., and Braeman, T. M. (1972). British fournal of Radiology, 45, 328

Dyson, M., Woodward, B., and Pond, J. B. (1971). Nature, 232, 572.

Evans, H. J. (1970). In Human Population Cytogenetics, ed. P. A. Jacobs, p. 191. Edinburgh, University Press.

Hill, C. R., Joshi, G. P., and Revell, S. H. (1972). British fournal of Radiology, 45,333 .

Lucas, M., Mullarkey, M., and Abdulla, U. (1972). British Medical fournal,

Macintosh, I. J. C., and Davey, D. A. (1970). British Medical Fournal, 3, 92. Macintosh, I. J. C., and Davey, D. A. (1972). British fournal of Radiology,

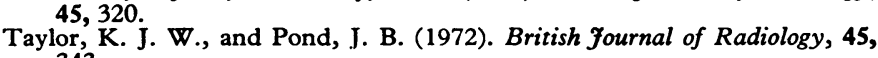
343.

United Nations Scientific Committee (1969). Report on the Effects of Atomic Radiation. New York, United Nations.

Watts, P. L., Hall, A.J., and Fleming, J.E.E. (1972) British fournal of Radio$\log y, 45,354$

\title{
Placental Lactogen Levels as Guide to Outcome of Threatened Abortion
}

\author{
P. A. R. NIVEN, J. LANDON, T. CHARD
}

British Medical fournal, 1972, 3, 799-801

\section{Summary}

The clinical value has been assessed of circulating placental lactogen levels as a pointer to the outcome in a patient with vaginal bleeding in early pregnancy. By using a semiautomated radioimmunoassay the normal range of values for the first and second trimesters has been established. In patients admitted with vaginal bleeding after the eighth week of gestation estimation of plasma human placental lactogen showed that patients with low levels were those in whom the abortion was completed during the first admission. Women whose pregnancies continued normally or who aborted after their first discharge from hospital had normal levels. In a small group sampled before the onset of bleeding but who later aborted the mean levels were lower than normal. This simple and inexpensive test can indicate those women in whom abortion is inevitable and could be used to reduce substantially the length of hospital stay in this common complication of early pregnancy.

\section{Introduction}

It is estimated that one in every seven pregnancies ends in abortion, and most such patients require hospital admission.

Departments of Obstetrics and Gynaecology and Chemical Pathology, St. Bartholomew's Hospital, London E.C.1

P. A. R. NIVEN, F.R.C.S., M.R.C.o.G., Senior Registrar

J. LANDON, M.D., Professor

T. CHARD, M.D., M.R.C.o.G., Senior Lecturer
In addition many women are admitted with vaginal bleeding in early pregnancy who achieve a successful outcome. On clinical grounds it is frequently impossible to distinguish between those pregnancies which are doomed and those which will proceed to fruition, and the diagnosis may be apparent only after several days' occupancy of an expensive hospital bed. A number of tests have been described which may help to make this important distinction, including the determination of plasma levels of human placental lactogen (Genazzani et al., 1969, 1971; Saxena et al., 1969; Singer et al., 1970; Haour et al., 1971; Spona and Janisch, 1971). These previous studies were based on relatively small numbers of patients and samples, and detailed analysis of results in relation to fetal outcome and normal levels was not presented.

The present study was undertaken to establish the normal range of circulating human placental lactogen levels during the first two trimesters and, based on these data, to assess the prognostic value of human placental lactogen determinations in patients with vaginal bleeding of sufficient severity to necessitate admission to hospital.

\section{Subjects and Methods}

The normal range was based on 736 samples from 634 singleton pregnancies of certain dates and compatible uterine enlargement in which no abnormality occurred before the $28: \mathrm{h}$ week of gestation.

A total of 422 samples were collected from 236 cases of bleeding in early pregnancy. This group included 141 subjects who aborted during their first admission, 14 who aborted 
after discharge from hospital, 12 who had ectopic pregnancies, and 69 who did not abort. The management of these patients was not governed by the results. It should be noted that in $66(47 \%)$ of those patients who aborted there were clinical doubts sufficient to delay evacuation of the uterus.

Human placental lactogen was estimated by a modification of the semiautomated technique described by Letchworth et al., (1971) using a lower concentration of antiserum (1 in 2,000 rather than 1 in 500) and overnight incubation. The resulting standard curve covers the range of concentrations encountered in the first half of pregnancy. All results were analysed after logarithmic transformation, and the significance of the difference between means was assessed by Student's $t$ test.

\section{Results}

The normal range is shown in Fig. 1. In the patients who aborted on first admission human placental lactogen levels were significantly lower than normal from the ninth week onwards $(P<0.01)$. In the 83 patients discharged from hospital with the pregnancy apparently intact human placental lactogen levels did not differ from normal (Fig. 2) regardless of the fact that 14 aborted subsequently. Levels were also normal in ectopic pregnancies.

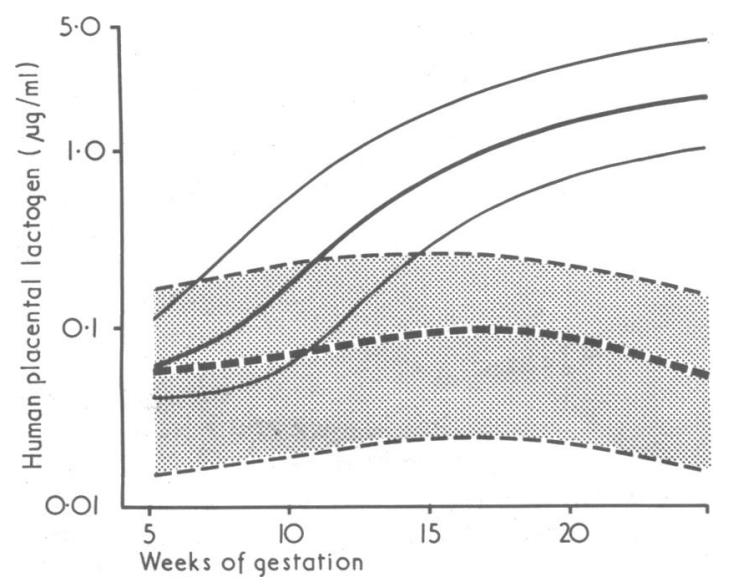
FIG. $1-$ Mean and range ( \pm 2 S.D.) of circulating human placental lactogen
levels in 634 normal patients from five to 24 weeks (solid lines), and in 141 subjects who aborted on first admission (interrupted lines and hatched area).

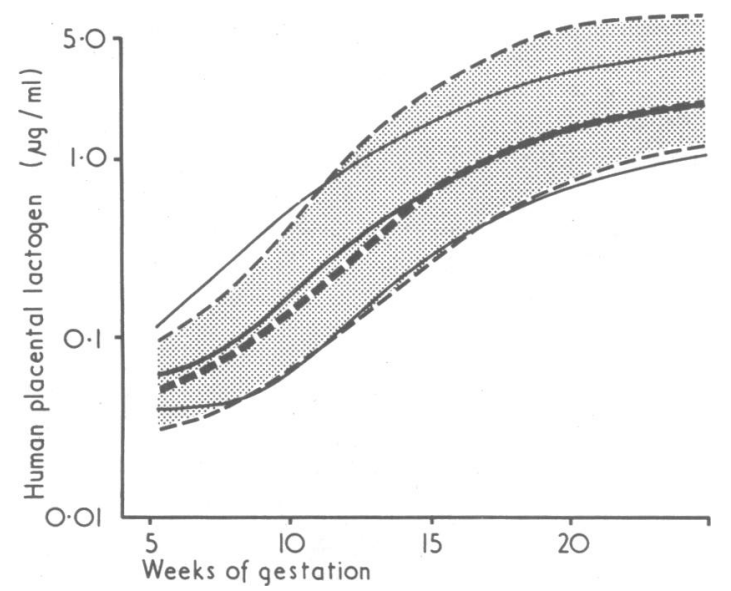

FIG. 2-Plasma human placental lactogen levels in 83 subjects discharged from hospital with an intact pregnancy. Mean and range for this group from hospital with an intact pregnancy. Mean and range for this group ( \pm 2 S.D.) is shown by the interrupted lines
In 28 subjects sampled before the onset of bleeding and who later aborted human placental lactogen levels were significantly lower than normal ( $P<0.001$ ) (Fig. 3).

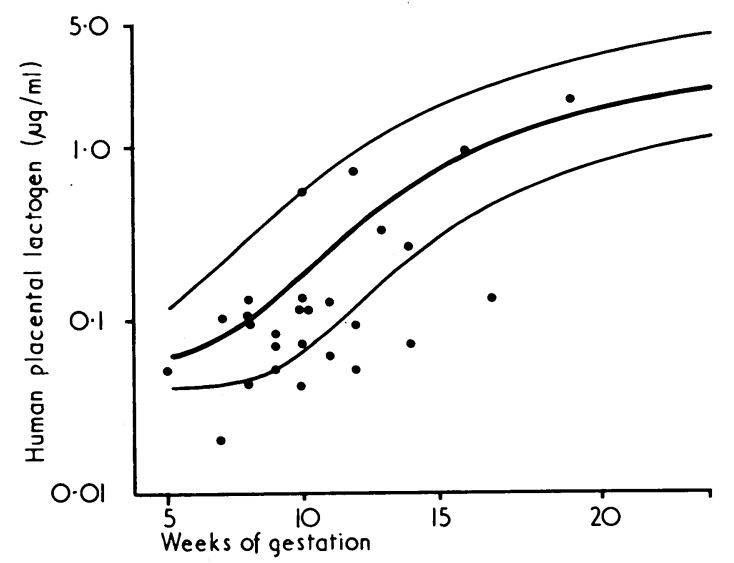

FIG. 3-Human placental lactogen levels in 28 subjects who subsequently aborted measured before the onset of bleeding. Mean and range of normal subjects is also shown.

\section{Discussion}

From the present evidence it is possible to reach two general conclusions. (1) Circulating human placental lactogen levels in subjects who present with vaginal bleeeding in early pregnancy and abort during first admission are lower than normal. (2) Circulating human placental lactogen levels in subjects with vaginal bleeding and an apparently favourable outcome on first admission, and in subjects with ectopic pregnancy, do not differ significantly from the normal range. Thus the test is likely to be of most value in those patients admitted with bleeding in early pregnancy in whom there is doubt about the short-term outcome ( 66 patients in the present series). In this group the prognostic value of a single low level is not fully obvious until the ninth week of pregnancy. In a patient before nine weeks, however, static or falling levels may indicate a poor prognosis, although the data in the present series were insufficient for this possibility to be fully evaluated.

Previous data on human placental lactogen levels in early pregnancy and abortion are shown in the Table. These studies suffer from a number of limitations, including small

Reported Data on Human Placental Lactogen Levels in Early Pregnancy and Abortion

\begin{tabular}{|c|c|c|c|c|}
\hline \multirow{2}{*}{ Source } & \multicolumn{2}{|c|}{$\begin{array}{l}\text { Normal } \\
\text { Subjects }\end{array}$} & \multicolumn{2}{|c|}{$\begin{array}{c}\text { Subjects with } \\
\text { Threatened Abortion }\end{array}$} \\
\hline & $\begin{array}{l}\text { No. of } \\
\text { Patients }\end{array}$ & $\begin{array}{c}\text { No. of } \\
\text { Samples }\end{array}$ & $\begin{array}{c}\text { No. of } \\
\text { Patients }\end{array}$ & $\begin{array}{l}\text { No. of } \\
\text { Samples }\end{array}$ \\
\hline $\begin{array}{l}\text { Saxena et al. (1969) } \\
\text { Genazzani et al.(1969) } \\
\text { Singer et al. (1970) } \\
\text { Haour et al. (1971) } \\
\text { Spona and Janisch (1971) } \\
\text { Genazzani et al. (1971) } \\
\text { Present study }\end{array}$ & $\begin{array}{r}62 \\
151 \\
20 \\
10 \\
34 \\
634\end{array}$ & $\begin{array}{r}62 \\
151 \\
20 \\
58 \\
34 \\
736\end{array}$ & $\begin{array}{r}7 \\
13 \\
9 \\
5 \\
50 \\
51 \\
224\end{array}$ & $\begin{array}{r}\overline{37} \\
14 \\
5 \\
63 \\
134 \\
410\end{array}$ \\
\hline
\end{tabular}

numbers, paucity of first-trimester abortions, inadequate correlation with the normal range and fetal outcome, and inconsistencies in the definition of threatened abortion. In so far as it is possible to make a comparison, the present results agree with those of Genazzani et al. $(1969,1971)$, which indicated that low human placental lactogen levels were found in pregnancies ending in abortion. These authors, however, used a normal range based on the standard error of the mean, which greatly underestimates the confidence limits to the population as a whole.

On the basis of the present results one can predict with reasonable accuracy by human placental lactogen determina- 
tions the outcome of a case of vaginal bleeding from the ninth week of pregnancy. With serial samples it may be possible to make this prediction before the ninth week. Thus, in the absence of contraindicating factors, such as maternal age or infertility, low levels would constitute grounds for evacuating the uterus without further delay. That the occasional normal pregnancy might be interrupted is mitigated by the fact that bleeding in early pregnancy carries a high risk of complications in the third trimester. It is also apparent that levels may be low before the onset of bleeding, though the overlap with the normal range would make prediction difficult in the individual subject.

Bleeding in early pregnancy is the commonest cause of emergency admission in young women. The average hospital stay for a patient with an incomplete or inevitable abortion is three days, compared with eight days for a threatened abortion (Department of Health and Social Security, 1968; St. Bartholomew's Hospital Statistics Department, personal communication, 1972). Since the average cost of maintaining a patient in a National Health Service bed exceeds $£ 12$ daily, an investigation costing less that $£ 1$ represents an excellent investment and greatly benefits the patient, who may otherwise have no spend several anxious days separated from her family.

We are indebted to the consultant, nursing, and secretarial staff of the North Middlesex Hospital, London, and to Miss Linda Howard, who performed the assays. The work was supported by grants from the Medical Research Council and the board of governors of St. Bartholomew's Hospital.

\section{References}

Department of Health and Social Security (1968). Report on Hospital Inpatient Enquiry, p. 98. London, H.M.S.O

Genazzani, A. R., Aubert, M. L., Casoli, M., Fioretti, P., and Felber, J.-P. (1969). Lancet, 2, 1385.

Genazzani, A. R., et al. (1971). Fournal of Obstetrics and Gynaecology of the British Commonwealth, 78, 577.

Haour, F., Cohen, E., and Bertrand, J. (1971). Revue Européenne d'Études Clinicales et Biologiques, 16, 124.

Letchworth, A. T., Boardman, R., Bristow, C., Landon, J., and Chard, T. (1971). Fournal of Obstetrics and Gynaecology of the British Commonwealth 78,542 .

Saxena, B. N., Emerson, K., and Selenkow, H. A. (1969). New England Fournal of Medicine, 281, 225.

Singer, W., Desiardins, P., and Friesen, H. G. (1970). Obstetrics and Gynecology, 36, 222.

Spona, J., and Janisch, H. (1971). Acta Endocrinologica, 68, 401.

\title{
Renal Failure in Acute Pancreatitis
}

\author{
D. GORDON, R. Y. CALNE
}

British Medical fournal, 1972, 3, 801-802

\section{Summary}

In three patients with acute pancreatitis complicated by renal failure recovery followed dialysis and treatment of associated complications. The records of cases of pancreatitis treated at Addenbrooke's Hospital, Cambridge, suggest that renal failure is a grave and not infrequent complication of acute pancreatitis.

\section{Introduction}

Acute renal failure is known to occur in acute pancreatitis (Howard and Jordan, 1960), but in a recent series (Trapnell, 1971) it was found to be one of the less common of the serious complications of the disease. Our experience is the reverse, that acute oliguria occurs with comparable frequency to the other serious complications of acute pancreatitis-namely, pseudocyst, abscess, and ileus-and must be treated energetically.

Out of 41 new cases of acute pancreatitis admitted under the care of the department of surgery at Addenbrooke's Hospital between July 1966 and April 197214 were associated with biliary tract disease and 7 experienced two or more attacks of pancreatitis. There were six deaths. Six patients $(15 \%)$ developed acute renal failure, all within two weeks of the onset of their illness, and three of these died. "Acute renal failure" has been regarded as present where there was a rise in blood urea to above $100 \mathrm{mg} / 100 \mathrm{ml}$, not relieved by simple fluid replacement, or when there were changes of acute tubular necrosis found at necropsy. Other complications included hypocalcaemia (cor-

Department of Surgery, University of Cambridge, Cambridge R. Y. CALNE, M.S., F.R.C.s., Professor of Surgery

Addenbrooke's Hospital, Cambridge

D. GORDON, M.B., M.R.c.P., Senior House Officer rected serum calcium less than $8.0 \mathrm{mg} / 100 \mathrm{ml}$ ) in 4 cases, pseudocyst or abscess ( 3 cases), and gastrointestinal bleeding ( 1 case).

This report concerns three cases where recovery followed dialysis and treatment of other associated complications.

\section{Case 1}

A 42-year-old American businessman was admitted with a five-day history of severe epigastric pain and vomiting. He was a moderate but not excessive drinker. He had had similar pains before but much less severe. There was pronounced abdominal tenderness. The serum amylase was 188 Somogyi units, and he was treated with antispasmodics and analgesics. Cholecystography and cholangiography were performed, and a barium-meal examination one week after admission suggested a pancreatic cyst. At laparotomy 11 days after admission a pancreatic cyst was drained by a catheter through the right loin.

Two days after operation he became oliguric, and six days after operation intermittent haemodialysis was begun. His general condition continued to decline. He developed atrial flutter and was treated with digoxin. Two weeks after operation he developed a pancreatic fistula through the drain site. On the next day there was massive bleeding through the fistula and per rectum. After transfusion of 20 bottles of blood a laparotomv was performed. The transverse colon had been digested bv th: inflammatory process around the pancreas, and two free ends of howel were completely separated. There was vigorous bleeding from the middle colic artery. The bleeding was controlled, and the colon brought to the abdominal wall as proximal and distal colostomies.

His condition remained extremely poor over the next few weeks, but renal function gradually returned and haemodialvsis was withdrawn. He was discharged after nearly four months in hospital. The continuity of the colon was restored at a later date. He remained well six years after his illness.

\section{Case 2}

A 58-year-old housewife was admitted with severe abdominal pain of three days' duration. On examination there was slight abdominal 